\title{
Simultaneous Satisfactory Design of Structural and Control Systems by Set-Based Design Method
}

\author{
[Naoko SASAKI, Aiguo MING, Haruo ISHIKAWA]
}

\begin{abstract}
The design method capable of simultaneously considering the factors related to control system and structural system, and satisfying the multiple design objects as well is proposed. This problem has usually trade-off factors and complex design situation. One of set-based design methods, preference set-based design (PSD), is applied to the simultaneous design problem of the arm structure with stepped shape under rotational motion. In PSD method, the design variables and performance variables are represented by interval set with designer's preference function and, solution sets are obtained considering high robustness and satisfaction of required performances. Simulation using PID controller in control engineering is performed. As a result, by using PSD method, each interval set of multiple design parameters related to the shape of the arm and the control system is obtained simultaneously satisfying multiple required performances appropriately.
\end{abstract}

Keywords - simultaneous design, set-based design, vibration control, structure/control interaction

\section{Introduction}

In the development of mechanical system, control function plays a greater role in the system, and optimal design of control system and structural system that have deep interaction with each other is considered to be of great importance. Therefore, in order to deal with the more technological advance of machinery, it is indispensable to achieve the simultaneous optimization of structural system and control system [1-4]. There, also, have been various practical studies relevant to this issue such as integrated design for hard disk drives and so on. In some practical cases [5], specified control target objects (structures) were provided in advance, and in the other cases, in addition to the characteristics of the control system, weight or damped oscillation characteristics is a factor governing the characteristics of the structure [6]. Then, the simultaneous optimization problems have often been formulated for the relatively simple cases, as the mathematical minimization problem of evaluation function [7-11].

Physical mechanisms of the mutual interaction of the both systems, however, are remained obscure. There are various issues to consider such as many and varied design variables, a large number of restrictions, complexity and multi-peak solution of evaluation function, and dynamic problem governed by motion equation with a large number of freedom that affects the interaction.

Naoko SASAKI, Ming AIGUO, Haruo ISHIKAWA

The University of Electro-Communications Japan
In mechanical system and electrical system such as robotics and automotive engineering, so-called PID (Proportional-Integral-Derivative) controller, including feedback system, is widely used to achieve desired mechanical or electrical behaviors $[12,13]$.

On the other hand, when the behavior of target object is in dynamical system, mass, center of gravity, inertial force, external force (torque), and resistance in proportion to velocity are generally considered in transfer function in control engineering including PID controller.

The shape and the size of the real target object, however, are not to be considered generally in PID controller. It often happens that the shape and the size differ while mass and/or the center of gravity are the same for some objects each other. Therefore, from the viewpoint of the actual design, it is thought, in this study, to be important that the real shape and size are also to be treated simultaneously with the control design.

Meanwhile, in order to present characteristics of the system in control engineering, some characteristics, like rise time, settling time, etc, for step-response which is used in this research are treated as design objectives (required performances) of control system.

From the viewpoint of the actual simultaneous treatment of controller and the design of shape and size, considering weight saving of an object, for example, its mass can be set as a design objective. In short, the elements of control engineering and weight saving (mass) are selected as design objects at the same time. In other words, the method to find the design solutions which satisfy multiple design objects is investigated.

On the other hand, the adjustment of the feedback gain is generally necessary in the feedback control design. And also, in the structural design, there are uncertainty such as the decision difficulty for the designer, the influence from other sections, the change of the palatableness of the user, in particular at the stage of a conceptual design and/or the initial design. Under the consideration for these adjustment and uncertainties, it is necessary to carry out the simultaneous design. Conventionally, design methodology for such situation was based on the point-based repetition design procedure.

In this study, we investigate the technique to enable design by the narrowing of the common set of some characteristics based on the range concept, not the repetition by the point base, considering the adjustments of control system and the uncertainties of the design of the structure system at the same time.

The purpose of the present research is to show that set (interval) solution that satisfies simultaneously multiobjectives in design problem over both of control engineering 
and mechanical engineering using set-based design method can be obtained.

In this research, MATLAB is used for simulation of the control (MATLAB is registered trade mark of MathWorks, USA).

\section{Set Concept in Control Design and Structural Design}

In the control design, there is the evaluation of transient characteristics and steady - state characteristics as the output for the input by the Step function. The value of the feedback gain influences these characteristics.

For example, the steady characteristic improves if there is a pole toward $s=0$, but the transient properties worsen. As how to decide of the feedback gain, Ziegler-Nichols ultimate sensitivity method is suggested. However, the value of the method is an aim to the last, in local spot situation, the values are obtained in a way of the trial and error.

In structural design, especially in conceptual or initial design, we meet various kinds of uncertainties, like the decision difficulty for the designer, the influence from other sections, the change of the palatableness of the user. In order to consider adjustment characteristics in the control engineering and uncertainties in the structure engineering, the idea of set-based design method $[14,15]$ is used in the present study. Especially the called Preference Set-Based Design (PSD) method, as a method to obtain set (interval) solutions of multiple design variables meeting a common space of multiobjective performances $[16,17]$ is applied. The method has been applied to practical problems of mechanical and structural engineering fields, but not to control engineering problem.

\section{Set-Based Design Method}

In the present study, main purpose is simultaneous design of control engineering and structural engineering, which are traditionally different fields. The design of the different fields can be integrally discussed if the concept of satisficing of the required performances is introduced [18].

In the set-based design methods, like fuzzy set-based method [19], interval set-based method [20], and probabilisticbased design method, preference set-based design method (PSD method) based on the satisficing is used in the present study. As one of the expression of the satisficing, in PSD method preference and robustness are defined. In this method, as shown in Fig. 1, required performances and design variables are represented by set with preference function. In addition, the preference numbers that are normalized as between 0 and 1 are used. The initial interval sets will be narrowed by the concept of the design preference and robustness defined by the preference function for the set. The procedure of the set-based design method is illustrated in Fig.2.
PSD method consists basically of set representation, set propagation, and set narrowing. Set-representation for design variables and requirement performances are expressed like Fig.1. Set propagation from the initial set with preference for design variables to required performance space is carried out to obtain the intersection solution space of design variables, where the requirements are satisfied. The propagation is carried by PSO (Particle Swan Optimization) method. In set narrowing process, the solution subset space with higher preference and robustness for all requirements is searched in the intersection solution, eliminating infeasible or unacceptable design subspaces. Finally, the narrowing process selects an optimal design subspace from a few feasible subspaces, which are more preferred by the designer and provides better design robustness .

\section{PID Control Method}

There are several concrete methods proposed for PID controller, such as P, PI, PD, PI-D controllers and so on. In this research, we used PI-D controller based on partial model matching technique [21-22]. This PI-D controller is presented by the following equation,

$$
\mathrm{u}(\mathrm{s})=\left(\mathrm{K}_{\mathrm{p}}+\mathrm{K}_{\mathrm{i}} / \mathrm{s}\right) \mathrm{e}(\mathrm{s})-\mathrm{K}_{\mathrm{d}} \mathrm{sy}(\mathrm{s})
$$

where $\mathrm{s}$ is a Laplace operator, $\mathrm{u}(\mathrm{s})$ is an input of controlled object, $\mathrm{y}(\mathrm{s})$ is an output of controlled object, $\mathrm{r}(\mathrm{s})$ is target (demanded) output value (shown in Fig. 3) and e(s) is the difference between the demanded set-value $r(s)$ and actual

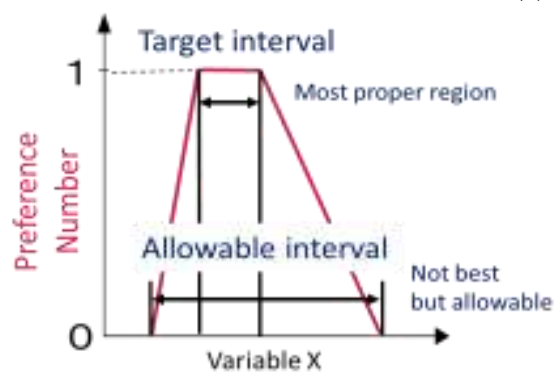

Figure 1. Representation of designer's preference.

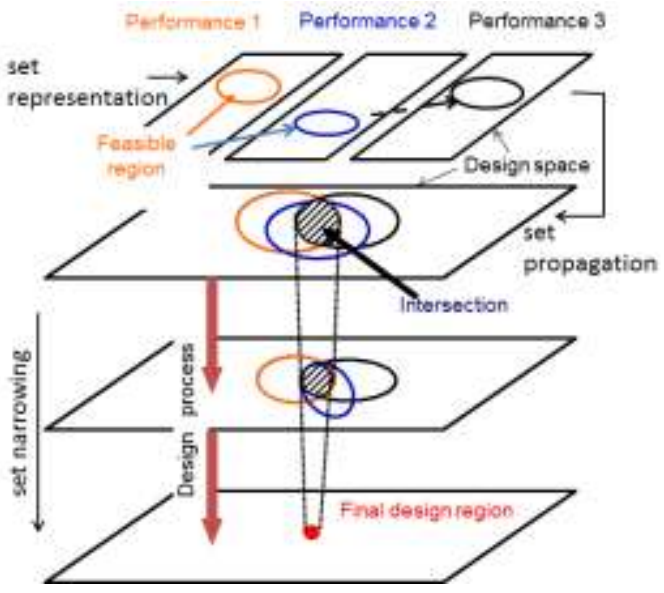

Figure 2. Set-based design method. 
output $y(s) . K_{p}$ is Proportional gain, $K_{i}$ is Integral gain, and $K_{d}$ is Derivative gain. A block diagram of PI-D controller is shown as Fig.3. In this figure, $\mathrm{C}(\mathrm{s})$ is controller and $\mathrm{P}(\mathrm{s})$ is controlled object. The input disturbance, $\mathrm{d}(\mathrm{s})$, is not considered this time.

The target value $r(s)$ is given as step function. While there are various factors to show transient characteristics of the step function, rise time $R_{s}$, percentage overshoot $A_{\max }$, and settling time $\mathrm{T}_{\mathrm{s}}$ (within $\pm 2 \%$ of the steady-state value), are used as typical examples in this research.

\section{v. Design Object}

In order to show the efficacy of set-based method to treat simultaneously both control design and shape/size design, linearized simulation around a certain value using PI-D controller was carried out for dynamic rotational motion arm as an example. In Fig. $4, \mathrm{~L}_{\mathrm{a}}, \mathrm{W}_{\mathrm{a}}$ and $\mathrm{L}_{\mathrm{b}}, \mathrm{W}_{\mathrm{b}}$ are length and width of region $a$ and $b$, respectively. In these parameters, $L_{b}$ and $W_{b}$ are design variables, while the values of length $L_{a}$, width $\mathrm{W}_{\mathrm{a}}$, and thickness are fixed, as $0.15[\mathrm{~m}], 0.05[\mathrm{~m}]$ and $0.1[\mathrm{~m}]$, respectively. As a result, design variables are three $\left(\mathrm{K}_{\mathrm{i}}, \mathrm{K}_{\mathrm{p}}\right.$ and $\left.\mathrm{K}_{\mathrm{d}}\right)$ for control system, and two $\left(\mathrm{L}_{\mathrm{b}}\right.$ and $\left.\mathrm{W}_{\mathrm{b}}\right)$ for structural system. In total, five design variables are used. $\theta$ is angle of rotation. The material of the arm is general resin.

\section{Mathematical Model and Simulation Model}

Mathematical model of dynamic rotational motion arm is presented as the following nonlinear differential equation.

$$
\mathrm{J} \ddot{y}(t)=-c \dot{y}(t)-M \lg \sin y(t)+u(t)
$$

Here, $" \mathrm{y}(\mathrm{t})=\theta(\mathrm{t})$ " is output (angle of rotation), $\mathrm{u}(\mathrm{t})$ is input torque to the arm. $\mathrm{M}$ is the mass of the controlled object, 1 is the distance from center of gravity to axis of rotation, $\mathrm{J}$ is the moment of inertia, $\mathrm{c}$ is the viscous friction coefficient $(0.695$ in this study), and $\mathrm{g}$ is the acceleration of gravity.

Step function is used for the input, then PI-D control was carried out to control the arm so that the difference between demanded output and actual output will be 0 .

In an example problem of PI-D control explained in section $\mathrm{V}$, the demanded output of arm angle is $\pi / 6$. In (2),

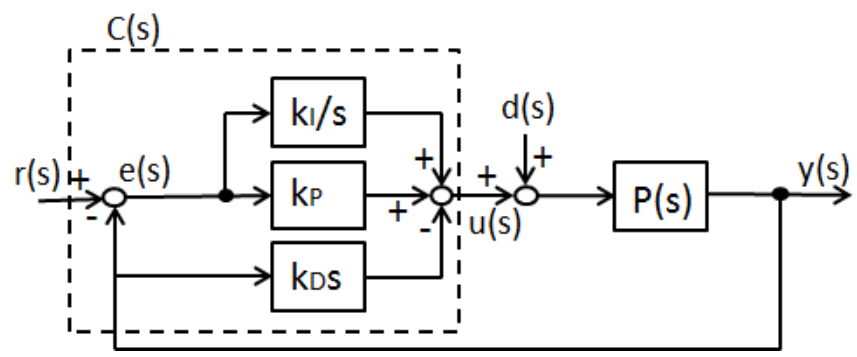

non-linear term is linearized around the angle of $\pi / 6$.

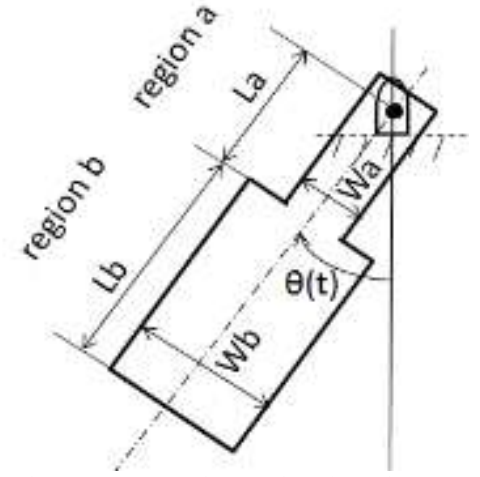

Figure 4. Dynamic rotational motion arm.

\section{vII. Application of Preference Set- Based Design (PSD) Method to an Example}

\section{A. Design Procedures}

Fig. 5 is the concrete design procedure of the set-based design method.

At stage A), the interval and preference of both the design variables $\left(\mathrm{L}_{\mathrm{b}}, \mathrm{W}_{\mathrm{b}}\right)$ of the shape/size and control variables $\left(\mathrm{K}_{\mathrm{i}}\right.$, $\mathrm{K}_{\mathrm{p}}$ and $\mathrm{K}_{\mathrm{d}}$ ) of controlled object are to be set.

In addition, required performances for control characteristic are the indexes mentioned in section IV (rise time $R_{s}$, settling time $T_{s}$, maximum overshoot $A_{\max }$ ), and mass, $\mathrm{M}$, of the arm for machine characteristic.

At the stage B), each performances are represented by response surface equations (quadratic polynomial). Practically, the performances are found according to the combinations of the three points (both ends and middle) within the set of design variables. This procedure is carried out by each level of the preference.

At the stage $\mathrm{C}$ ), the performance intervals for the design variables and preference at the stage A) are obtained for each preference number by using response surface expressions of

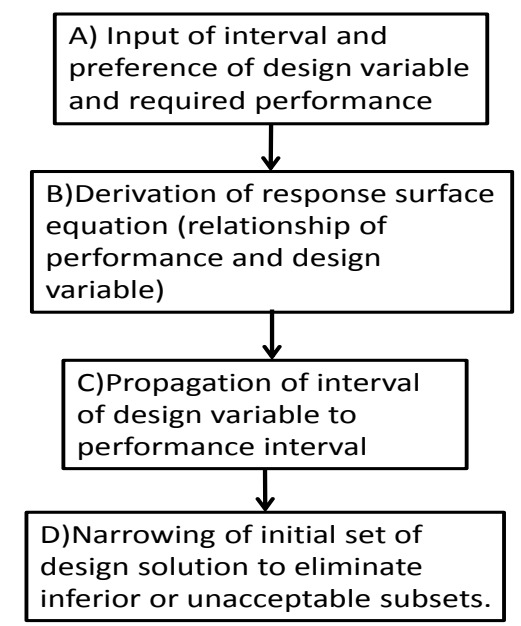

Figure 5. Procedure of preference set-based design method. 
B). Particle Swarm Optimization method [23-24] is used for set propagation.

At the stage D), how the performance interval with preference obtained at stage C) satisfies the initial interval of required performances with preferences is investigated. To do so, the preference and robustness are measured. The solution set of the design variables are selected considering the robustness and the preference.

\section{B. Result of Preference Set-Based Design (PSD)}

The relationship between the design variables and the performances are required to carry out the PSD method. The simulation of PI-D control was conducted using MATLAB.

Then, with the results (rise time, overshoot and settling time), the set-based design was carried out using the initial sets of the five design variables and four performances. Two cases with different requirements are examined.

The initial sets of the design variables and required performances are shown in Table I . For example, the initial sets of $\mathrm{W}_{\mathrm{b}}$ and $\mathrm{A}_{\max }$ are shown by dotted lines in Fig. 6 and Fig. 7, respectively.

As the result of the calculation by PSD method, the solution sets of the design variables and the related performances are obtained (Table II). The set solutions are narrowed through the design procedures in Section VII.

TABLE I.

Design Variables \& ReQuiRed PeRformances(CASe1)

\begin{tabular}{|c|c|}
\hline Design Variables & Initial Sets \\
\hline Length of region $\mathrm{b}, \mathrm{L}_{\mathrm{b}}[\mathrm{m}]$ & {$[0.1,0.2]$} \\
\hline Width of region $\mathrm{b}, \mathrm{W}_{\mathrm{b}}[\mathrm{m}]$ & {$[0.1,0.2]$} \\
\hline Integral gain, $\mathrm{K}_{\mathrm{i}}$ & {$[10,20]$} \\
\hline Proportional gain, $\mathrm{K}_{\mathrm{p}}$ & {$[10,20]$} \\
\hline Derivative gain, $\mathrm{K}_{\mathrm{d}}$ & {$[0.1,0.5]$} \\
\hline
\end{tabular}

\begin{tabular}{|c|c|}
\hline Performances & Requirements \\
\hline Rise time, $\mathrm{R}_{\mathrm{s}}[\mathrm{s}]$ & $\leqq 0.15$ \\
\hline Maximum overshoot, $\mathrm{A}_{\max }[\%]$ & $\leqq 20$ \\
\hline Settling time, $\mathrm{T}_{\mathrm{s}}[\mathrm{s}]$ & $\leqq 3.0$ \\
\hline Mass, $\mathrm{M}[\mathrm{kg}]$ & $2 \leqq \mathrm{M} \leqq 3$ \\
\hline
\end{tabular}

TABLE II. NARROWED SOLUTION SET

\begin{tabular}{|c|c|c|}
\hline & Case 1 & Case 2 \\
\hline Length of region $\mathrm{b}, \mathrm{L}_{\mathrm{b}}[\mathrm{m}]$ & {$[0.10,0.13]$} & {$[0.10,0.11]$} \\
\hline Width of region $\mathrm{b}, \mathrm{W}_{\mathrm{b}}[\mathrm{m}]$ & {$[0.13,0.15]$} & {$[0.15,0.16]$} \\
\hline Integral gain, $\mathrm{K}_{\mathrm{i}}$ & {$[15.0,17.5]$} & {$[16.7,17.5]$} \\
\hline Proportional gain, $\mathrm{K}_{\mathrm{p}}$ & {$[10,12.5]$} & {$[10,10.8]$} \\
\hline Derivative gain, $\mathrm{K}_{\mathrm{d}}$ & {$[0.1,0.2]$} & {$[0.1,0.13]$} \\
\hline Rise time, $\mathrm{R}_{\mathrm{s}}[\mathrm{s}]$ & {$[0.10,0.15]$} & {$[0.12,0.14]$} \\
\hline Maximum overshoot, $\mathrm{A}_{\max }[\%]$ & {$[8.35,19.2]$} & {$[9.30,13.4]$} \\
\hline Settling time, $\mathrm{T}_{\mathrm{s}}[\mathrm{s}]$ & {$[1.25,2.69]$} & {$[1.57,2.00]$} \\
\hline Mass, $\mathrm{M}[\mathrm{kg}]$ & {$[2.0,2.63]$} & {$[2.25,2.47]$} \\
\hline
\end{tabular}

The solution set of $\mathrm{W}_{\mathrm{b}}$ is shown by solid line in Fig. 6, for example. The line with circles shows the possibility of the performance for the initial sets of five design variables. The interval shown by the solid line of Fig. 7 is the performance corresponding to the solution sets of Case 1 .

Next, the influence of the maximum overshoot rate $A_{\max }$, one of the performance, is considered as Case 2. As an example, $A_{\max }$ is set to be below $15 \%$ in this case (Fig. 8) while the other conditions are the same as Case 1 . The result of the design parameters is obtained (Table II ).

As explained, narrowed solution sets are obtained under each condition. To verify the validity of the solution sets, the following substitution was conducted. Middle point values of the every design parameters of the narrowed intervals of design parameters are used to get the point value of required performances. As a result of the substitution, each value of performance parameters is obtained in required performance (Table I ).
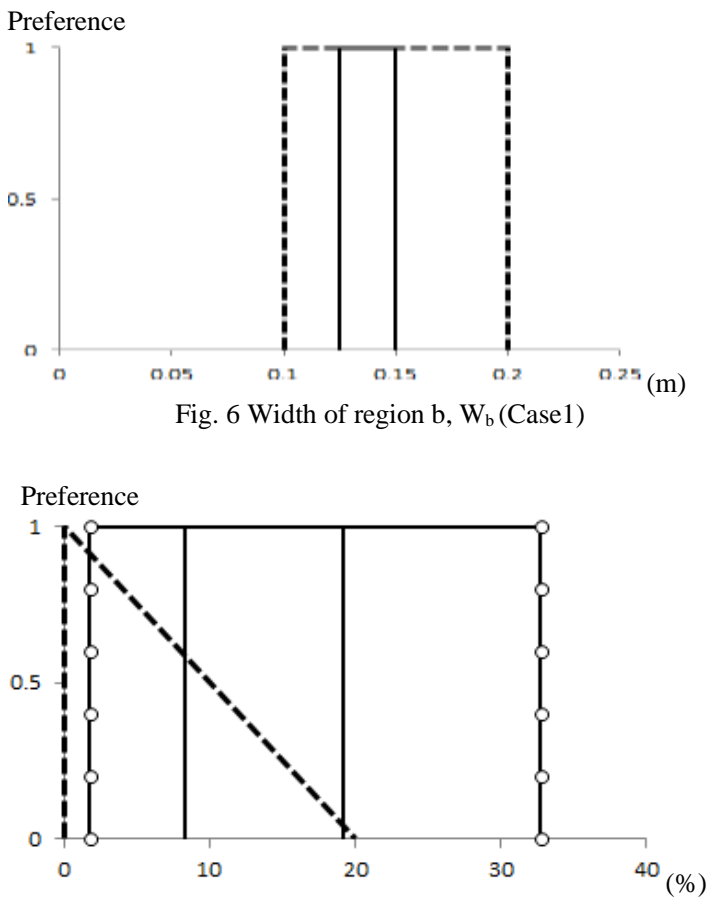

Fig. 7. Maximum overshoot, $A_{\max }$ (Case1)

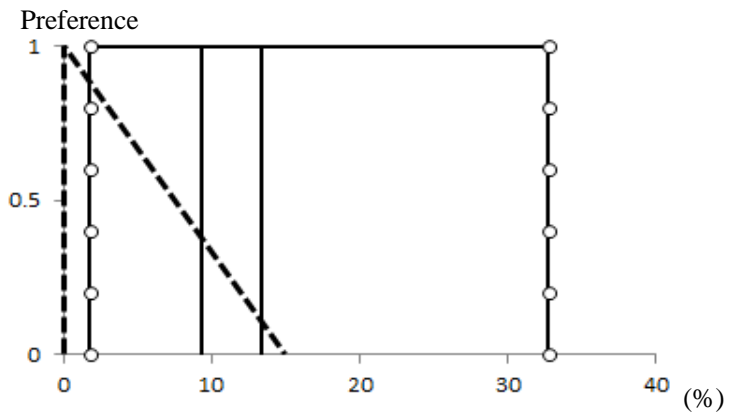

Fig. 8. Maximum overshoot, $A_{\max }($ Case2) 


\section{vIII. Conclusion}

The design method capable of considering the factors related to the design of PID controller and the shape/size of controlled object at the same time, and satisfying the multiple design objects as well is proposed. This method is different from the traditional point-based design method. In other words, the design variables and performance variables are represented by interval set with designer's preference and, solution sets can be found considering high satisfaction of required performances.

As a practical example, a problem of dynamic motion arm is used to show the efficacy of this method. The solution sets of five design variables are obtained simultaneously, satisficing four required performances. This research shows that the method which has been applied to mechanical designs can be applied to the simultaneous designs of structural system and control system.

\section{References}

[1] R.K. Mehra, "Optimization of measurement schedules and sensor designs for linear dynamic systems," IEEE Trans., AC-21-1, pp. 55-64, 1976.

[2] C.S. Kubrusly and H. Malebranche, "Sensors and controllers location in distributed systems-A survey," Automatica, 21-2, pp. 117-128 , 1985.

[3] P.T. Kabamba and R.W. Longman, "An integrated approach to reducedorder control theory," Optimal Control Applications \& Methods, 4, pp. 405-415, 1983

[4] T.T. Soong, "Active structural control," John Wiley \& Sons, 1990

[5] M. Nakaminami, T. Tokuma, T. Moriwaki, and K. Nakamoto, Optimal structure design methodology for compound multiaxis machine tools- I - Analysis of requirement and specifications-, “ Int. J. of Automation Technology, Vol.1 No. 2, pp. 78-86, 2007.

[6] G. Obinata, "Simultaneous optimal design of structural system and control system," Journal of the Society of Instrument and Control Engineers, 36,4, pp. 254-261, 1997. (in Japanese)

[7] I. Kajiwara and A. Nagamatsu, "Optimum design of structure and control systems by modal analysis," The Japan Society of Mechanical Engineers, (C)60-570, pp.368-373, 1994. (in Japanese)

[8] F. Hara, "Optimization of pipe-support allocation by newral network," The Japan Society of Mechanical Engineers, (C)58-550,pp. 1728-1734, 1992. (in Japanese)

[9] H. Hatano, "Optimization by GA," Journal of the Society of Instrument and Control Engineers," 32-1, pp. 52-57, 1993. (in Japanese)

[10] N.S. Khot and H. Öz, "Structural-control optimization with $\mathrm{H} 2$ and $\mathrm{H}$ constraints," 34th SDM (Structures, Structural Dynamics and Materials) Conference, AIAA-93-1470-CP, pp.1429-1437, 1993.

[11] R. 1.Fox and M. P.Kapoor, "Rates of change of eigenvalues and eigenvectors", AIAA j., 6-12, pp. 2426-2429, 1968.

[12] K.Astrom and T. Hagglund, "PID controllers: Theory, design and tuning,", 2nd ed., Instrument Society of America, 1995.

[13] T. Hagiwara, K. Yamada, I. Murakami,Y. Ando, S. Matsuura, and S. Aoyama, "An application of the modified PID control system for heat flow experiment," Int. J. of Automation Technology Vol.4 No.5, pp. 469-476, 2010

[14] A.Ward, J. K. Liker, J. J. Cristiano, and II D. K. Sobek, "The second Toyota paradox: how delaying decisions can make better cars faster", Sloan Management Review; Vol. 36, No. 3, ,pp. 43-61, 1995.

[15] II DK. Sobek, A.C. Ward, and J. K. Liker, "Toyota's principles of setbased concurrent engineering", Sloan Management Review, Vol. 40, No. 2, pp. 67-83, 1999.

[16] YE. Nahm and H. Ishikawa, "Representing and aggregating engineering quantities with preference structure for set-based concurrent engineering," Concurrent Engineering: Research and Applications, Vol.13, No.2, pp.123-133,2005.

[17] YE. Nahm and H. Ishikawa, "Novel spaced-based design methodology for preliminary engineering design," Int. J. Adv. Manuf. Technol, Vol.28, pp.1056-1070, 2006

[18] Herbert A. Simon, “The Science and The Artificial," MIT press, 1996.

[19] M.J. Scott, et al., "Aggregation functions for engineering design tradeoffs", Fuzzy Sets and Systems, Vol. 99, No. 3, pp. 253-264 ,1998.

[20] W.W. Finch, et al., "A set-based system for eliminating infeasible design in engineering problems dominated by uncertainty", Proc. of the ASME Design Engineering Technical Conference, DETC97/DTM-3886 ,1997.

[21] T. Kitamori,"A method of control system design based upon partial knowledge about controlled process," Journal of the Society of Instrument and Control Engineers, Vol.15, No.4, pp.549-555, 1979. (in Japanese)

[22] M. Kawata and K. Nishioka,"Plain control engineering based on MATLAB/Simulink," Morikita Publishing Co., Ltd., pp.92-93, 2001. (in Japanese)

[23] J. Kennedy and R. Eberhart, "Particle swarm optimization," Proceedings of IEEE International Conference on Neural Networks IV, pp. 19421948, 1995

[24] Y. Shi, and R.C. Eberhart, "A modified particle swarm optimizer," Proceedings of IEEE International Conference on Evolutionary Computation, pp. 69-73, 1998

About Authors:

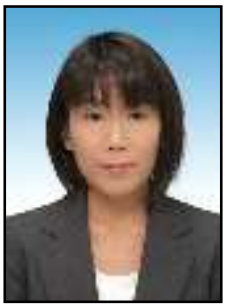

Naoko SASAKI

She is an assistant professor at The University of Electro-Communications, Japan. Her research focuses on design methodology.

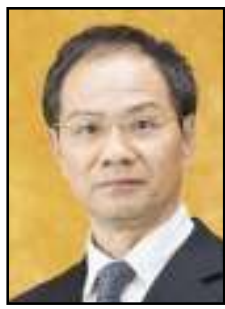

Ming AIGUO

$\mathrm{He}$ is a professor at The University of Electro-Communications, Japan. His research focuses on robotics and mechatronics.

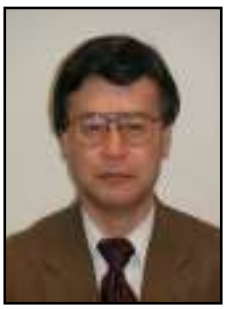

Haruo ISHIKAWA

$\mathrm{He}$ is a professor at The University of Electro-Communications, Japan. His research focuses on design methodology. Based on the methodology, he has designed various products. 